\section{The Dynamic Model Provides the Best Description of the Chill Process on 'Sirora' Pistachio Trees in Australia}

\author{
Jianlu Zhang ${ }^{1}$ \\ Pistachio Growers' Association Incorporated, RMB 2570, Robinvale, \\ Victoria 3549, Australia
}

Cathy Taylor

Department of Primary Industries, P.O. Box 905, Mildura, Victoria 3502, Australia

Additional index words. Utah Model, Chilling Hour Model, budbreak, Pistacia vera

\begin{abstract}
Determining the chilling requirement for 'Sirora' pistachio (Pistacia vera L.) production in Australia and monitoring winter chill accumulation is desirable to allow growers to take timely mitigating action in years of insufficient chill. Based on greenhouse work, historical data analysis, and field validation, the Chilling Hour, Utah, and Dynamic Models were compared. The Dynamic Model produced the best determination for fulfillment of chilling requirement with 59 chill portions. The required number of growing degree-hours above $4.4^{\circ} \mathrm{C}$ from chill fulfillment to $50 \%$ bloom was 9633 . Relations among the level of fulfillment of chilling requirement, bloom delay, and yield are discussed.
\end{abstract}

Cool winter temperatures are required by many fruit and nut trees that originate from temperate or cool subtropical regions to overcome winter dormancy (Erez, 2000; Samish, 1954; Saure, 1985). Sufficient winter chill results in homogeneous and simultaneous flowering (Luedeling et al., 2009c). When fruit and nut crops are grown outside their traditional growing regions, estimating the amount of chill required and that which is available is important (Luedeling et al., 2009a).

"In order to select appropriate fruit and nut species and cultivars for the climate of a given site, researchers have developed chilling models, which convert temperature records into a metric of coldness" (Luedeling et al., 2009c).

The chilling process in trees is not completely understood and it is difficult to produce a model that perfectly explains the accumulation of winter chill (Dennis, 2003; Erez, 2000; Saure, 1985). Chilling models can be used to determine the chilling requirement of a cultivar and the chill available at a particular location; however, they are not completely accurate (Luedeling et al., 2009a). Quantitative measurements of winter chill are required to determine the suitability of a cultivar to a particular growing region, to determine the timing of management practices such as applying rest-breaking chemicals, and to predict

Received for publication 15 Oct. 2010. Accepted for publication 16 Jan. 2011.

We thank Graeme Sanderson, Industry and Investment, NSW, Australia, for permitting the use of pistachio trees for this research and Eike Luedeling, World Agroforestry Centre (ICRAF), Nairobi, Kenya, for helpful discussion of the manuscript.

${ }^{1}$ To whom reprint requests should be addressed; e-mailpgai@iinet.net.au. yield potential. Understanding the effect of dormancy completion level on interannual variation can also be facilitated by the use of chilling models (Luedeling et al., 2009c).

The Chilling Hour Model is one of the earliest, developed in the 1930s (Chandler and Tufts, 1934) and 1940s (Yarnell, 1940) and is the simplest. Bennett (1949) quantified winter chill as the number of hours 0 to $7.2^{\circ} \mathrm{C}$ (32 to $\left.45^{\circ} \mathrm{F}\right)$, whereas Weinberger (1950) suggested using the number of hours $7.2^{\circ} \mathrm{C}$ or less $\left(45^{\circ} \mathrm{F}\right)$ during the winter season. Luedeling et al. (2009c) proposed that "freezing temperatures did not contribute to winter chill accumulation" and used 0 to $7.2^{\circ} \mathrm{C}$ and denoted it the Chilling Hour Model. However, it has been found that high temperatures have a negative chill contribution (Richardson et al., 1974). Erez and Lavee (1971) reported that $10^{\circ} \mathrm{C}$ was approximately half as efficient in breaking dormancy as $6^{\circ} \mathrm{C}$. The Utah Model, a weighted Chilling Hour Model with high temperatures having a negative effect on chilling accumulation, was developed in the 1970s (Richardson et al., 1974). This model has been adapted to adjust to varying climatic conditions. Norvell and Moore (1982) extended effective temperature ranges compared with the Utah Model. Shaltout and Unrath (1983) adjusted the relationship between chill units and temperatures by assigning greater chill contribution to lower temperatures and more negative effect to temperatures greater than $21{ }^{\circ} \mathrm{C}$ (North Carolina Model). Disregarding chill units accumulated on days when there is a negative total has been found to be more suitable in marginal areas in South Africa (Allan et al., 1995). This model is called the Positive Utah Model (Linsley-Noakes et al., 1995).

All these models treat the effect of hourly temperatures on chilling accumulation, in mathematical terms, as a time-homogeneous stationery process. In other words, they assume that $2 \mathrm{~h}$ at the same temperature recorded at different times in a long-term observation contribute equally to the breaking of dormancy (Fishman et al., 1987a). Results obtained by Erez et al. (1979) in experiments with periodically changed temperatures contradicted this assumption. 'Redskin' peach plants were exposed to differing temperatures for cycles of $1,3,6$, and $9 \mathrm{~d}$ with temperatures of 4 to $6{ }^{\circ} \mathrm{C}$ for two-thirds of the cycle length and $24^{\circ} \mathrm{C}$ for the remaining one-third of the cycle. Each cycle was repeated until all plants were exposed to 1150 chilling hours, or 575 chill units based on the Utah Model. However, plants showed significantly different responses; when plants were exposed to cycles of greater length, a higher percentage of budbreak was observed. The same amount of high temperature when applied in long cycles resulted in less chilling negation. Because stationary processes do not sufficiently explain these results, nonstationary and time-inhomogeneous processes should be introduced to chilling models. This is implemented in the Dynamic Model.

The Dynamic Model (Fishman et al., $1987 \mathrm{a}, 1987 \mathrm{~b})$ was developed in the 1980s and defined a new concept for the negation process. Winter chill is assumed to accumulate in a two-step process. Cold temperatures initially result in the formation of an intermediate chilling product; high temperatures can destroy this product. Once a critical amount of this chilling product has accumulated, it converts to a chill portion, which cannot be destroyed. A certain chill portion accumulation indicates fulfillment of chilling requirement. Although a few papers support the Dynamic Model on peach (Allan et al., 1995; Erez et al., 1990), apricot (Ruiz et al., 2007), and walnut (Luedeling et al., 2009c), the Dynamic Model has not been widely adopted (Luedeling et al., 2009a). Studies of chill requirements in pistachio have mainly used the Chilling Hour and Utah Models (Afshari et al., 2009; Rahemi and Pakkish, 2009). The amount of chill required for 'Sirora' pistachio grown in Australia has not been established.

After chill fulfillment, temperatures above some base level will result in growth and bud development (Richardson et al., 1975). Growing degree-hours (GDH) are the number of hours of heat required for budbreak or bloom after the chilling requirement is fulfilled. A few models for GDH have been proposed in this area (Anderson and Richardson, 1987; Richardson et al., 1974, 1975).

The Australian pistachio industry was established in southeastern Australia in the early 1980s and nut bearing began in the early 1990s with full yield production reached in the early 2000s. The climate is classified as warm grassland using a modified Köppen classification system (Stern et al., 2000). In general, winter maximum temperatures range from 16 to $19^{\circ} \mathrm{C}$ and minimum temperatures 4 to $8{ }^{\circ} \mathrm{C}$ with $5 \mathrm{~d}$ of $0{ }^{\circ} \mathrm{C}$ or less. Figure 1 shows two extreme winters at two locations within this region. In Winter 2005, chill was low, whereas high chill was experienced in 
Winter 2006. Typical winters fall between these extremes.

In Spring 2005, budbreak was clearly delayed, for most orchards, by 1 month with some buds breaking 2 months and even 4 months late. This suggested a lack of winter chill. Winter oil application is a useful agent to overcome low-chill winters (Beede and Ferguson, 2002) and is used by growers to promote even and timely budbreak. The decision to apply oil to alleviate low chill needs to be made before 31 Aug. Mid-late August is the best time for winter oil application in Australia or mid-late February in the United States (northern hemisphere) (Beede and Ferguson, 2002). Thus, by mid-August, growers need a prediction of chill accumulation to decide whether to apply oil.

This article reports on the evaluation of three chill models to determine the chilling requirement for 'Sirora' pistachio trees in southeastern Australia to calculate chill accumulation using historical data and to predict the necessity for winter oil application after mild winters.

\section{Materials and Methods}

\section{Models}

Chilling Hour Model. The Chilling Hour Model sums the number of hours with temperatures between 0 and $7.2{ }^{\circ} \mathrm{C}$ from 1 May to 31 Aug. each year.

The Utah Model. Hourly temperatures are transferred into Utah chill units according to Table 1 (Richardson et al., 1974). Because negative chill units accumulate above $16^{\circ} \mathrm{C}$ and the average late summer temperatures exceed this threshold, a plot of chill unit accumulation in late summer gives an increasingly negative curve until average temperatures drop below negation levels $\left(16{ }^{\circ} \mathrm{C}\right)$ and positive chill unit accumulation begins. This maximum negative accumulation can be used as the starting point for physiological chill unit accumulation. Such a "point event" works well in temperate zone climates with definite seasons (Seeley, 1996). We began calculating chill unit accumulation on 1 Mar. and ended on 31 Aug. each year. The equivalent time in the northern hemisphere is 1 Sept. to the end of February.

The Dynamic Model. The equations used to calculate chill portions are more complex than the other models. Although they are difficult to derive from the original publications, Luedeling et al. (2009c) extracted them from a spreadsheet commonly used by practitioners:

$$
\begin{aligned}
& x_{i}=\frac{e^{\text {slp } \cdot \text { tetmlt } \cdot\left(T_{k}-\text { tetmlt }\right) / \mathrm{T}_{k}}}{1+e^{\text {slp } \text { tetmlt } \cdot\left(T_{k}-\text { tetmlt }\right) / T_{k}}} \\
& x_{s}=\frac{a_{0}}{a_{1}} \cdot e^{\frac{e_{1}-e_{0}}{T_{k}}}
\end{aligned}
$$

$$
a k_{1}=a_{1} \cdot e^{-\left(e_{1} / T_{k}\right)}
$$

inter $_{E}=X_{s}-\left(X_{s}-\right.$ inter $\left._{S}\right) \cdot e^{-a k_{1}}$

$$
\begin{aligned}
& \text { inter }_{s}= \begin{cases}t=t_{0} & \quad: 0 \\
t>t_{0} \Lambda \text { inter }_{E_{t-1}}<1 & : \text { inter }_{E_{t-1}} \\
t>t_{0} \Lambda \text { inter }_{E_{t-1}} \geq 1 & : \text { inter }_{E_{t-1}} . \\
& \left(1-X_{i}\right)\end{cases} \\
& \text { delt }= \begin{cases}t=t_{0} & : 0 \\
t>t_{0} \Lambda \text { inter }_{E}<1 & : 0 \\
t>t_{0} \Lambda \text { inter }_{E} \geq 1 & : x_{i} \cdot \text { inter }_{E}\end{cases}
\end{aligned}
$$
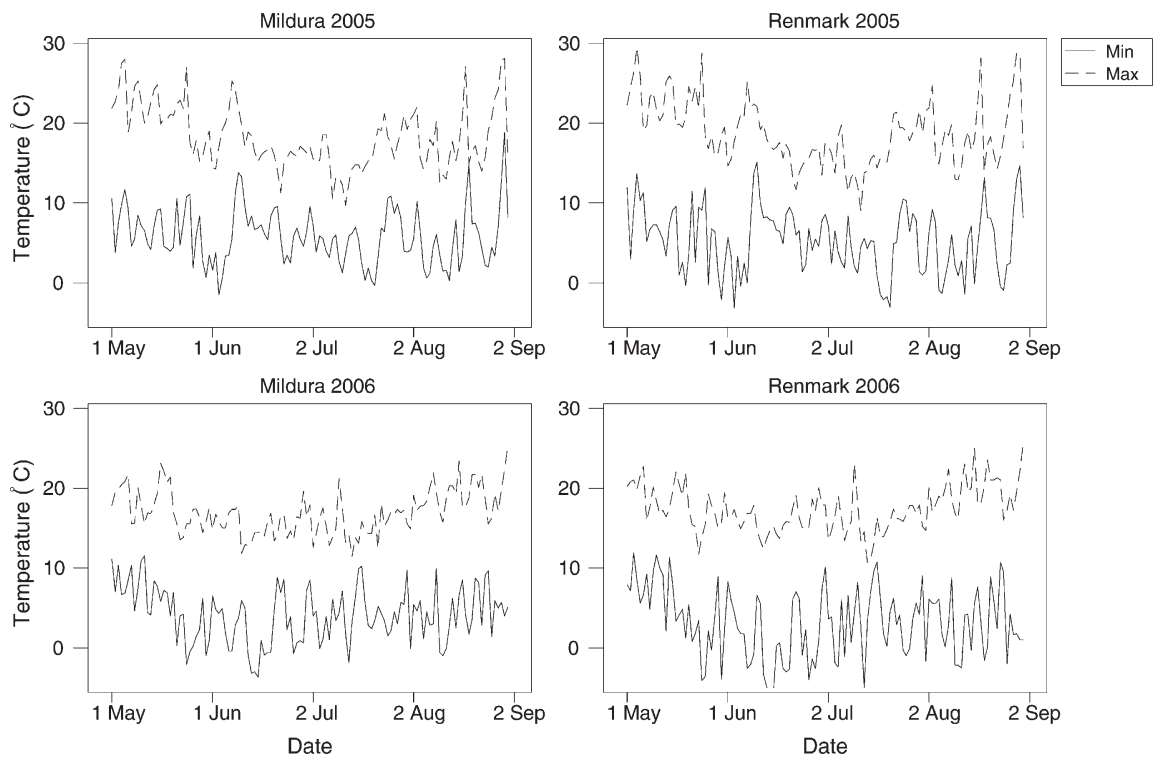

Fig. 1. Daily maximum and minimum winter temperatures (May to September) for Mildura and Renmark 2005 and 2006

Table 1. Conversion of selected temperatures to chill units (Richardson et al., 1974).

\begin{tabular}{lccccccc}
\hline & Less than & & & & & & Greater \\
Temperature $\left({ }^{\circ} \mathrm{C}\right)$ & 1.4 & $1.5-2.4$ & $2.5-9.1$ & $9.2-12.4$ & $12.5-15.9$ & $16-18$ & than 18 \\
\hline Chill units & 0 & 0.5 & 1 & 0.5 & 0 & -0.5 & -1 \\
\hline
\end{tabular}

$$
\text { chill portions }_{t}=\left\{\begin{aligned}
t=t_{0} & : \text { delt } \\
t \geq t_{0} & : \text { delt }+ \text { chill } \\
\text { portions } &
\end{aligned}\right.
$$

The experimentally derived constants slp, tetmlt, $\mathrm{a}_{0}, \mathrm{a}_{1}, \mathrm{e}_{0}$, and $\mathrm{e}_{1}$, were set to $1.6,277$, $139,500,2.567 \times 10^{18}, 4153.5$, and $12,888.8$, respectively (Erez et al., 1988). $\mathrm{T}_{\mathrm{k}}$ is the measured hourly temperature in Kelvin, whereas $t$ denotes the time during the season (in hours) with $t_{0}$ being the starting point of chilling accumulation. As a result of the self-limiting effect of the destruction of the intermediate product, this model starts accumulation automatically. However, our calculation started on 1 Mar. and ended at 31 Aug. each year.

The number of portions accumulated between 15 Aug. and 31 Aug. was also calculated to allow the estimation of the number of portions that needed to be accumulated by 15 Aug. to enable timely decisions on the application of dormancy-breaking chemicals to be made.

Growing degree-hours. A model for GDH from Shaltout and Unrath (1983) was used. It is

$$
\mathrm{GDH}=\sum\left(\mathrm{Tm}-4.4^{\circ} \mathrm{C}\right)
$$

where $\mathrm{Tm}$ is temperature at a given hour in the day; $4.4{ }^{\circ} \mathrm{C}$ is the base temperature, or, if any hour has a temperature $4.4^{\circ} \mathrm{C}$ or less, it was recorded as 0 .

Greenhouse. In Winter 2006 to 2010, 10 shoots from five 15- to 19-year-old 'Sirora' pistachio trees were taken weekly from Dareton Research Station, Industry and Investment, New South Wales (long. $34^{\circ} 05^{\prime} \mathrm{S}$, lat. $\left.142^{\circ} 00^{\prime} \mathrm{E}\right)$. The trees were grown under normal cultivation without winter oil application. The shoots were put into a vase with water in a greenhouse at $23 \pm 1{ }^{\circ} \mathrm{C}$ for 3 weeks. After 3 weeks, percentages of buds reaching the cluster appearance stage (Zhang, 2006) were recorded. When $50 \%$ budbreak occurred in 2 consecutive weeks, fulfillment of chill requirement was said to have been reached in the first of those weeks. Chilling hours, chill units, and chill portions were calculated using hourly temperature records taken from a weather station located at the research station. Each year the flowering date, when $50 \%$ of flower buds had reached the loose cluster stage, was recorded for these five trees.

Correlation between historic winter chill and observed yields and validation of model prediction of chill accumulation. The majority of pistachio production in Australia is located around Renmark (long. $34^{\circ} 11^{\prime} \mathrm{S}$, lat. $140^{\circ} 45^{\prime} \mathrm{E}$ ) and Mildura (long. $34^{\circ} 11^{\prime} \mathrm{S}$, lat. $142^{\circ} 09^{\prime}$ E). Historical hourly temperature data from Bureau of Meteorology weather stations from both Renmark and Mildura were used to calculate chill accumulation using the three models for the period 1999 to 2005 . Data from 2006 to 2010 were used to validate each model's determination of chill accumulation. Where there were several 
consecutive missing hourly values, these values were estimated by averaging the temperatures immediately before and after. No hourly data were available for Mildura or Renmark on 8 July 2001; the missing values were estimated using the daily minimum and maximum temperature. Flowering dates $(50 \%$ of flowers at loose cluster stage) in these areas were also recorded for orchards with and without oil to compare the effects of winter oil application on flowering dates since 2006. Between 2000 and 2010 , yield was recorded from four orchards in the Renmark region and six in the Mildura region.

\section{Results}

Greenhouse. Chill in Winter 2006 was high. Shoots collected on 10 Aug. reached $50 \%$ budbreak in the greenhouse, indicating fulfillment of chill requirement. In the field, $50 \%$ bloom occurred on 20 Sept. (Table 2). This was extremely early compared with historical bloom dates, which were approximately early October. Chill in Winter 2008 and 2010 was high. The chill requirement was fulfilled on 3 Sept. and 25 Aug., respectively, and the bloom date was close to average. Winters 2007 and 2009 had low chill accumulation. The dates of fulfillment of chill requirement were late and the $50 \%$ bloom dates were much later than average.

Each winter the Dynamic Model produced similar results with chilling fulfillment occurring between 58 to 62 chill portions (Table 2). The difference between the lowest and the highest was only $6.5 \%$. Variations in fulfillment of chilling requirement from the Chilling Hour and Utah Models were much greater with $39 \%$ (412 to 677 chilling hours) and $30 \%$ (752 to 1123 chill units) difference between the lowest and highest, respectively.

GDH requirements for bloom, after fulfillment of the chilling requirement, were also calculated based on greenhouse work. In Spring 2006, at Dareton Research Station, GDH from fulfillment of chilling requirement (10 Aug.) to $50 \%$ bloom was 9633 . Based on GDH of 9633 , 50\% bloom dates were predicted and listed in Table 2. In 3 of the 4 years, the predicted bloom date was within $1 \mathrm{~d}$ of the actual date. However, the prediction in 2007 was very poor; by the end of August, chill portions were below the chilling requirement with bloom in the field occurring $20 \mathrm{~d}$ after the predicted date. The bloom date for the five trees at Dareton was later than other orchards in that area, which bloomed only 2 weeks after the predicted date.

Correlation between historic winter chill and observed yield. Figure 2 shows the biennial bearing pattern of pistachio production between 2000 and 2010 in selected orchards in the Mildura and Renmark regions. In the Mildura region, the biennial bearing pattern was clear; 2001, 2003, 2005, 2007, and 2009 were "on"-years. In the Renmark region, 2001, 2005, 2007, and 2009 were clearly "on"-year crops but 2003 was not. This resulted in very even yield between 2001 and
2004 but a large increase in 2005. This indicates factors other than biennial bearing influence yield. Winter chill for Renmark in 2002 was low. This is supported by observations of uneven budbreak. This low chill may have led to relatively low yield in the "on"year of the biennial bearing cycle.

Another low-chill winter in both the Mildura and Renmark regions was Winter 2005. Bloom in 2005 was late and in some orchards bloom was delayed by more than 4 weeks and some flowers were still emerging in Feb. 2006, just before harvest.

Results from the Winter 2006 greenhouse work (Table 2) were used as standards for each chill model to compare historical chill and industry yield records. The Dynamic Model correctly indicated the chill in all years when matched to evenness of flowering (Table 3) and yield records (Fig. 2). However, the Chilling Hour Model incorrectly indicated that 1999 and 2003 were low-chill years for Renmark. In these years, yield data and evenness of budbreak indicated sufficient chill. Similar inaccurate predictions were made for Mildura in 1999, 2001, 2002, 2003, and 2004. The Utah Model indicated poor chill for Renmark in 1999, 2001, 2003, and 2004 when industry yield records indicated sufficient chill. Average yield in Renmark was low in 1999 as a result of orchards there were just beginning to bear commercial quantities. Budbreak in these orchards was even. The Utah Model indicated low chill in Mildura in 2002 and 2005; however, in 2002, observations showed even budbreak and high yield.

Model prediction validation. Since Winter 2006, chilling accumulations were calculated using the three models. Winter 2006 had very high chill (Table 4) and warm weather in September led to budbreak in spring being $10 \mathrm{~d}$ earlier than usual. However, in 2006,

Table 2. Accumulation of chilling hours, chill units, and chill portions for chilling requirement each winter with predicted (based on 9633 GDH established in 2006) and actual bloom dates and field GDH (twigs taken from Dareton Research Station, Industry and Investment, New South Wales). ${ }^{\mathrm{z}}$

\begin{tabular}{lcccccrr}
\hline Winter & $\begin{array}{c}\text { Chilling } \\
\text { fulfillment date }\end{array}$ & $\begin{array}{c}\text { Chilling } \\
\text { hours }\end{array}$ & $\begin{array}{c}\text { Chill } \\
\text { units }\end{array}$ & $\begin{array}{c}\text { Chill } \\
\text { portions }\end{array}$ & $\begin{array}{c}50 \% \text { bloom } \\
\text { date predicted }\end{array}$ & $\begin{array}{c}50 \% \text { bloom } \\
\text { date in the field }\end{array}$ & GDH \\
\hline 2006 & 10 Aug. & 645 & 990 & 59 & & 20 Sept. & 9,633 \\
2007 & 13 Sept. & 677 & 919 & 58 & 8 Oct. & 7 Nov. & 17,297 \\
2008 & 3 Sept. & 569 & 1,078 & 62 & 9 Oct. & 10 Oct. & 9,818 \\
2009 & 9 Sept. & 412 & 752 & 60 & 17 Oct. & 16 Oct. & 9,411 \\
2010 & 25 Aug. & 535 & 1,123 & 61 & 9 Oct. & 10 Oct. & 10,063 \\
\hline
\end{tabular}

${ }^{\mathrm{z}}$ Chilling hours calculated from 1 May to chilling fulfillment date and chill units and chill portions calculated from 1 Mar. to chilling fulfillment date.

$\mathrm{GDH}=$ growing degree-hours.

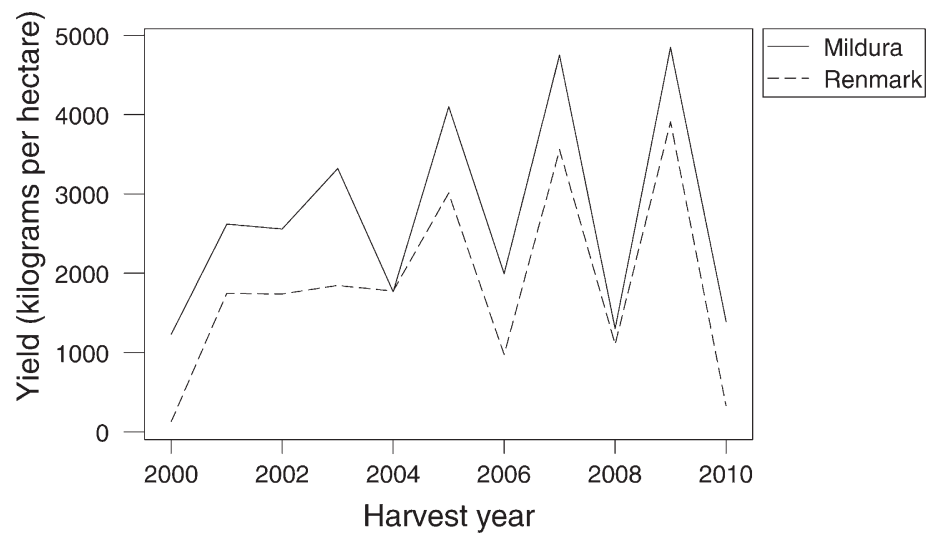

Fig. 2. Average yields (kilograms per hectare) for six orchards in the Mildura region and four orchards in the Renmark region, 2000-2010.

Table 3. Observations of evenness of budbreak and chilling accumulations calculated using historical data from weather stations at Mildura and Renmark. ${ }^{\mathrm{z}}$

\begin{tabular}{|c|c|c|c|c|c|c|c|c|}
\hline \multirow[b]{2}{*}{ Winter } & \multicolumn{2}{|c|}{ Evenness of budbreak } & \multicolumn{2}{|c|}{ Chilling hours $645^{y}$} & \multicolumn{2}{|c|}{ Chill units $990^{\mathrm{y}}$} & \multicolumn{2}{|c|}{ Chill portions $59^{y}$} \\
\hline & Renmark & Mildura & Renmark & Mildura & Renmark & Mildura & Renmark & Mildura \\
\hline 1999 & Even & Even & $602^{\mathrm{x}}$ & $600^{x}$ & $818^{x}$ & 1028 & 59 & 66 \\
\hline 2000 & Even & Even & 706 & 715 & 1097 & 1291 & 70 & 75 \\
\hline 2001 & Even & Even & 645 & $635^{x}$ & $955^{x}$ & 1062 & 64 & 63 \\
\hline 2002 & Uneven & Even & 591 & $640^{x}$ & 764 & $940^{x}$ & 56 & 59 \\
\hline 2003 & Even & Even & $620^{x}$ & $629^{x}$ & $953^{x}$ & 1037 & 63 & 64 \\
\hline 2004 & Even & Even & 652 & $625^{\mathrm{x}}$ & $971^{x}$ & 1100 & 63 & 65 \\
\hline 2005 & Very & Very & 604 & 574 & 829 & 894 & 55 & 57 \\
\hline
\end{tabular}

${ }^{\mathrm{z}}$ Chilling hours calculated from 1 May to $31 \mathrm{Aug}$. and chill units and chill portions calculated from $1 \mathrm{Mar}$. to 31 Aug.

${ }^{y}$ Chill standard for each model calculated from 2006 chill accumulation at Dareton Research Station.

${ }^{\mathrm{x}} \mathrm{A}$ poor match between the observed evenness of budbreak and the chill predicted by the model. 
when Renmark only had 974 chill units (Table 4 ), this was not reflected in the observed budbreak and yield was excellent. All the models determined that in Renmark Winter 2007 would have low chill and this was reflected in the observed lack of evenness in budbreak. In that year, winter oil application advanced budbreak more than 2 weeks. Chill in Mildura in 2007 was satisfactory; however, chill units observed at Mildura were below the standard although budbreak was even and yield was reasonable. Chill in 2008 was satisfactory; winter oil advanced bloom by 1 week or less. Winter 2009 had low chill and all models determined this. Orchards without winter oil application in 2009 still had flower buds bursting in early December and the effects of low chill on crop yields were clearly visible. In 2010, the Chilling Hour Model predicted that chill would be satisfactory in Renmark but in Mildura, there was one less chilling hour than required; the other two models predicted high chill. Observations of even budbreak and winter oil application advancing budbreak by less than 1 week indicate satisfactory chill.

Over the 5 years, the Dynamic Model produced more reliable determination than the other two models.

Decision-making for winter oil application. Table 5 lists the increase in chill portions between 15 Aug. and 31 Aug. in Mildura and Renmark. The minimum gain in the last 12 years was three in Mildura and four in Renmark. To allow for variance, we assume that two chill portions can be obtained in this period. Thus, 57 chill portions accumulated by 15 Aug. indicates chilling requirements will be fulfilled. If chill accumulation is below this on 15 Aug., winter oil should be applied.

\section{Discussion}

The pistachio industry in Australia requires a reliable model to determine the accumulation of chill to assist in orchard management decisions. Provided the role of chilling models as nothing more than proxies for winter chill is recognized, using a chilling model to quantify both a cultivar's chilling requirement and the amount of chill available at a given location becomes possible, if not completely accurate (Luedeling et al., 2009a). The Dynamic Model has been found to be better or at least equal to the Utah Model in studies at various locations (Alburquerque et al., 2008; Allan et al., 1995; Luedeling et al., 2009a; Ruiz et al., 2007; Viti et al., 2010). In our study, the range of chill portions measured was relatively small (58 to 62 ). In late August and early September, between two and six chill portions can accumulate in 1 week and had we collected samples more frequently, the range may have been smaller. After 5 years of observations it appears that the chill requirement for 'Sirora' pistachio is 59 chill portions. In those years when chill portions reached 59, no reduction in yield resulting from chill was observed. The only year when greenhouse experiments indicated a chill requirement of less than 59 chill portions was 2007, which was also the only year when poor correlation between predicted and actual bloom was observed at the Dareton Research Station. This discrepancy may be the result of inconsistencies in the

Table 4. Observations of evenness of budbreak and chilling accumulations calculated from weather station data at Mildura and Renmark to predict sufficiency of chill. ${ }^{\mathrm{z}}$

\begin{tabular}{|c|c|c|c|c|c|c|c|c|}
\hline \multirow[b]{2}{*}{ Winter } & \multicolumn{2}{|c|}{ Evenness of budbreak } & \multicolumn{2}{|c|}{ Chilling hours $645^{y}$} & \multicolumn{2}{|c|}{ Chill units $990^{y}$} & \multicolumn{2}{|c|}{ Chill portions $59^{y}$} \\
\hline & Renmark & Mildura & Renmark & Mildura & Renmark & Mildura & Renmark & Mildura \\
\hline 2006 & Even & Even & 727 & 773 & $974^{x}$ & 1137 & 68 & 72 \\
\hline 2007 & Uneven & Even & 573 & 688 & 837 & $970^{x}$ & 55 & 59 \\
\hline 2008 & Even & Even & 657 & 662 & 1122 & 1152 & 65 & 68 \\
\hline 2009 & $\begin{array}{l}\text { Very } \\
\text { uneven }\end{array}$ & $\begin{array}{l}\text { Very } \\
\text { uneven }\end{array}$ & 445 & 488 & 678 & 823 & 55 & 58 \\
\hline 2010 & Even & Even & 645 & $644^{x}$ & 1030 & 1198 & 65 & 69 \\
\hline
\end{tabular}

${ }^{\mathrm{z}}$ Chilling hours calculated from 1 May to 31 Aug. and chill units and chill portions calculated from 1 Mar. to 31 Aug.

${ }^{\mathrm{y}}$ Chill standard for each model calculated from 2006 chill accumulation at Dareton Research Station.

${ }^{\mathrm{x}} \mathrm{A}$ poor match between the observed evenness of budbreak and the chill predicted by the model.

Table 5. Number of dynamic portions accumulated at 15 Aug. and 31 Aug. at Mildura and Renmark and the number of portions accumulated in the interval.

\begin{tabular}{lccccccc}
\hline & \multicolumn{3}{c}{ Mildura } & & \multicolumn{3}{c}{ Renmark } \\
\cline { 2 - 4 } \cline { 6 - 7 } Yr & 15 Aug. & 31 Aug. & Gain & & 15 Aug. & 31 Aug. & Gain \\
\hline 1999 & 61 & 66 & 5 & 54 & 59 & 5 \\
2000 & 64 & 75 & 11 & & 60 & 70 & 10 \\
2001 & 54 & 63 & 9 & 56 & 64 & 8 \\
2002 & 52 & 59 & 7 & & 49 & 56 & 7 \\
2003 & 54 & 64 & 10 & 53 & 63 & 10 \\
2004 & 62 & 65 & 3 & 58 & 63 & 5 \\
2005 & 51 & 57 & 6 & 49 & 55 & 6 \\
2006 & 66 & 72 & 6 & 63 & 68 & 5 \\
2007 & 55 & 59 & 4 & 51 & 55 & 4 \\
2008 & 60 & 68 & 8 & 56 & 65 & 9 \\
2009 & 55 & 58 & 3 & 51 & 55 & 4 \\
2010 & 58 & 69 & 11 & 56 & 65 & 9 \\
Average gain & & & 6.9 & & & & 6.8 \\
\hline
\end{tabular}

10-shoot samples collected. At Renmark, chill portions were less than 59 in 2002, 2005, 2007, and 2009, all years when observations of uneven budbreak and poor yield also indicated that these were years with insufficient winter chill. Mildura had chill portions of less than 59 in 2005 and 2009, which correspond with observations of uneven budbreak and low crop if no winter oil was applied.

The large variation produced by the other two models makes selecting a chilling requirement value for these difficult. There was poor correspondence between the calculated chill and observed budbreak with both the Chilling Hour and Utah Models. The Chilling Hour Model focuses on hourly temperatures between 0 and $7.2^{\circ} \mathrm{C}$. However, in the Mildura and Renmark regions, hourly temperatures $7.2{ }^{\circ} \mathrm{C}$ or less are usually infrequent as shown in Figure 1. Even in the cold winter of 2006, there were still many days when the minimum temperature was greater than $7.2^{\circ} \mathrm{C}$. Providing temperatures between 7.2 and $12.9^{\circ} \mathrm{C}$ is useful for the chill process; it is obvious that the Chilling Hour Model is not suitable for those areas.

If the chilling requirement of 990 chill units determined in 2006 is used to interpret historical temperature records in Renmark, all years except 2000, 2008, and 2010 should have had insufficient winter chill. Even for 2006, a very high chill year, the chill units accumulated in Renmark were still below the "standard." Of course, if the 752 chill units calculated in 2009 were used as a "standard," almost all years would have been deemed to have had sufficient chill. In Winter 2006 in Renmark, warm temperatures resulted in $249 \mathrm{~h}$ with -1 unit and $243 \mathrm{~h}$ with -0.5 units. In Winter 2008 in Renmark, the Utah Model had the highest values in the last 12 years when there were only $194 \mathrm{~h}$ with -1 and $231 \mathrm{~h}$ with -0.5 in Renmark. However, not only did both the Chilling Hour Model and the Dynamic Model have lower values in 2008 than 2006, but bloom in 2006 was earlier and shorter than in 2008. So, even when the Utah Model indicated that chill in 2006 was low, the plant response indicated that chill was high. The frequent warm temperatures experienced in winter resulting in so many negative units make the Utah Model unsuitable at least for the Renmark region.

Average winter temperatures in Renmark and Mildura are very similar. However, Renmark has higher maximum and lower minimum temperatures than those of Mildura. Under this situation, Renmark usually has more chilling hours $7.2^{\circ} \mathrm{C}$ or less than Mildura because it has lower minimum temperatures. However, Renmark usually has less chilling units than Mildura because it has higher maximum temperatures. When the Chilling Hour Model $\left(0\right.$ to $\left.7.2{ }^{\circ} \mathrm{C}\right)$ is used, the hours less than $0{ }^{\circ} \mathrm{C}$ at Renmark do not account for any extra chill and this results in a similar amount of chilling hours as Mildura.

Although the Dynamic Model has not been widely used, it has advantages in regions where warm temperatures sometimes occur during winter. The major reason is that the 
Dynamic Model treats hourly temperatures as a non-stationary and time-inhomogeneous process.

The Chilling Hour and Utah Models add or multiply a factor and then add each hour together. Whatever the order of accumulation, when the sum reaches a given value, these models indicate that the chill requirement has been fulfilled. Does the chill process really only require these individual accumulations? The Dynamic Model takes into account the temperatures that precede and follow a particular time as well as those occurring at that particular time. Erez et al. (1979) states that "the period of chilling duration and the frequency of high temperature infusion during the chilling period are of prime importance." For example, "temperatures of 13 to $16{ }^{\circ} \mathrm{C}$ may enhance response if cycled with lower temperatures" (Dennis, 2003). This indicates that those hours are not time-homogeneous. The effect of the second hour is based on what happens in the first hour, whereas the effect of the third hour is based on what happens in the first $2 \mathrm{~h}$. This is the core principle of the Dynamic Model.

Predicted temperature increases resulting from climate change will reduce the amount of available winter chill (CSIRO and Bureau of Meteorology, 2007). Any reduction in winter chill will present challenges to growers with changes in management practices and perhaps even cultivars needed to accommodate new growing conditions (Luedeling and Brown, 2010; Luedeling et al., 2009b). Consequently, it is important to identify the most suitable model for this region and also one that will continue to be useful in the future in a climate with increased temperatures. Luedeling et al. (2009a) indicated that the Dynamic Model has the least variation compared with the Chilling Hour and Utah Models and our studies have shown that for the pistachio-growing regions of southeast Australia, this is also true. The Dynamic Model has also been shown to be the model that best describes the budbreak and yield responses of pistachio to chill in southeast Australia.

Between leaf fall and budbreak, there are two phases necessary to break dormancy, chill requirement, and heat requirement. It is not known when these two phases start and end; Luedeling et al. (2009a) tried to calculate this "intersection point" based on "phenological observations." Harrington et al. (2010) believe "that chilling and forcing can occur at the same time (in the temperature range where they overlap)." If that is the case, then there will always be some inaccuracies when using existing chill and heat accumulation models to predict bloom dates in regions that experience warm temperatures during the "chilling" season. For this study, we assumed that heat requirement starts immediately after chill requirement fulfillment. From our observations, when winter chill is satisfied, then the assumption that heat accumulation only starts when the chill requirement is achieved appears to be valid and the prediction of bloom dates is accurate. However, when winter chill is low, prediction of bloom dates is less accurate and it therefore appears that chill and heat accumulation is a much more complex process. Based on calculations from the Dynamic Model, predictions of 50\% bloom dates were within $1 \mathrm{~d}$ of the actual bloom date for all years except 2007 (Table 2). Predictions were also made for the Mildura and Renmark regions with reasonable results except 2007 (unpublished data). In 2007, temperatures in August, September, and October were higher than average. This resulted in the chill requirement fulfillment being achieved much later than usual. Fishman et al. (1987a) assumed that dormancy completion could be proportional to an accumulated amount of some changes in plants such as an accumulation of a chemical substance or changes in physical structures and called this the "dormancy breaking factor (DBF)." When the chill requirement is fulfilled within the normal period, it may be assumed that all buds obtain enough DBF. When the chill requirement is not fulfilled within the normal period, the DBF produced only satisfies a proportion of buds. These buds break earlier, whereas some other buds still require DBF and break late. This may explain why we observed differences in budbreak in the greenhouse and in the field. In Winter 2007, the shoots collected and placed in the greenhouse had accumulated enough DBF for $50 \%$ budbreak to occur, whereas those left on the tree did not.

A relationship among chill accumulation, $50 \%$ budbreak in the greenhouse, bloom in the field, and yield has yet to be established. Many authors (Erez and Lavee, 1971; LinsleyNoakes and Allan, 1994; Richardson et al., 1974; Shaltout and Unrath, 1983) have tested chill fulfillment but they mainly focus on budbreak. However, growers are more interested in the influence of chill accumulation on yield and how the ability to predict chill accumulation can influence orchard management practices to maximize yield. It is important to include consideration of the yield when comparing models.

In the pistachio industry in Australia, winter oil has been commonly used in most orchards for some years. Oil application in mid-late August may advance budbreak by 0 to 4 weeks or more compared with orchards without winter oil application. From our observation in the field, if by 31 Aug., chill portions were 68 or greater, oil application had no influence on bloom date or yield. When chill portions were between 61 and 67 , oil application advanced bloom by $\approx 1$ week but our observations indicated that it had no influence on yield. When chill portions were between 59 and 60, we observed no clear reduction in yield; however, oil application advanced bloom by $\approx 2$ weeks. When chill portions were 58 or less, without application of oil, yield was reduced and oil application advanced bloom by 3 or more weeks.

Winter oil application plays a major role in pistachio production during low-chill years. All data shown were based on chill accumulations to 31 Aug. each year. However, the decision to apply oil to alleviate low chill needs to be made before 31 Aug. Mid- late August is the best time for winter oil application in Australia. Thus, by mid-August, growers need a prediction of chill accumulation to decide whether to apply oil. Based on our data, 57 chill portions accumulated by 15 Aug. provides a reasonable level of confidence that chilling requirements will be fulfilled. If chill accumulation is below this on 15 Aug., winter oil should be applied. Otherwise, the possibility of reduction in yield is high. Five years of practical application shows this estimate ( 57 chill portions) works well. Although occasionally this model will underestimate the final chill portions such as in Winter 2010 when 56 chill portions had accumulated by 15 Aug. and nine chill portions accumulated between 15 Aug. and 31 Aug., growers have still accepted it as a management tool that provides security in years when sufficient chill may not accumulate.

\section{Literature Cited}

Afshari, H., A. Tajabadipour, H. Hokmabadi, and M.M. Moghadam. 2009. Determining the chilling requirements of four pistachio cultivars in Semnan province (Iran). African J. of Agr. Res. 4:55-59.

Alburquerque, N., F. García-Montiel, A. Carrillo, and L. Burgos. 2008. Chilling and heat requirements of sweet cherry cultivars and the relationship between altitude and the probability of satisfying the chill requirements. Environ. Exp. Bot. 64:162-170.

Allan, P., G. Rufus, G.C. Linsley-Noakes, and G.W. Matthee. 1995. Winter chill models in a mild subtropical area and effects of constant $6{ }^{\circ} \mathrm{C}$ chilling on peach budbreak. Acta Hort. 409:9-17.

Anderson, J.L. and E.A. Richardson. 1987. The Utah chill unit/flower bud phenology models for deciduous fruit: Their implication for production in subtropical areas. Acta Hort. 199: $45-50$.

Beede, R.H. and L. Ferguson. 2002. Effect of rootstock and treatment date on the response of pistachio to dormant applied horticultural mineral oil. Acta Hort. 591:53-56.

Bennett, J.P. 1949. Temperature and bud rest period. California Agr. 3:9-12.

Chandler, W.H. and W.P. Tufts. 1934. Influence of the rest period on opening of buds of fruit trees in spring and on development of flower buds of peach trees. Proc. Amer. Soc. Hort. Sci. 30: 180-186.

CSIRO and Bureau of Meteorology. (2007). Climate change in Australia. Technical Report. 5 Jan. 2011. <http://climatechangeinaustralia.com.au/ documents/resources/TR_Web_Ch5i.pdf>.

Dennis, F.G. 2003. Problems in standardizing methods for evaluating the chilling requirements for the breaking of dormancy in buds of woody plants. HortScience 38:347-350.

Erez, A. 2000. Bud dormancy; phenomenon, problems and solutions in the tropics and subtropics, p. 17-48. In: Erez, A. (ed.). Temperate fruit crops in warm climates. Kluwer Academic, Dordrecht, The Netherlands.

Erez, A., S. Fishman, Z. Gat, and G.A. Couvillon. 1988. Evaluation of winter climate for breaking bud rest using the Dynamic Model. Acta Hort. 232:76-89.

Erez, A., G.A. Couvillon, and C.H. Hendershott. 1979. Effect of cycle length on chilling negation by high-temperatures in dormant peach leaf buds. J. Amer. Soc. Hort. Sci. 104:573576. 
Erez, A., S. Fishman, G.C. Linsley-Noakes, and P. Allan. 1990. The dynamic model for rest completion in peach buds. Acta Hort. 276:165174.

Erez, A. and S. Lavee. 1971. Effect of climatic conditions on dormancy development of peach buds. 1. Temperature. J. Amer. Soc. Hort. Sci. 96:711-714

Fishman, S., A. Erez, and G.A. Couvillon. 1987a. The temperature dependence of dormancy breaking in plants: Mathematical analysis of a two-step model involving a cooperative transition. J. Theor. Biol. 124:473-483.

Fishman, S., A. Erez, and G.A. Couvillon. 1987b. The temperature dependence of dormancy breaking in plants-Computer simulation of processes studied under controlled temperatures. J. Theor. Biol. 126:309-321.

Harrington, C.A., P.J. Gould, and J.B. St.Clair. 2010. Modeling the effects of winter environment on dormancy release of Douglas-fir. For. Ecol. Mgt. 259:798-808.

Linsley-Noakes, G.C. and P. Allan. 1994. Comparison of two models for the prediction of rest completion in peaches. Sci. Hort. 59:107-113.

Linsley-Noakes, G.C., M. Louw, and P. Allan. 1995. Estimating daily positive Utah chill units using daily minimum and maximum temperatures. J. Southern African Soc. Hort. Sci. 5:19-23.

Luedeling, E. and P.H. Brown. 2010. A global analysis of the comparability of winter chill models for fruit and nut trees. Intl. J. Biometeorol. 1-11.
Luedeling, E., M. Zhang, G. McGranahan, and C. Leslie. 2009a. Validation of winter chill models using historic records of walnut phenology. Agr. For. Meteorol. 149:1854-1864.

Luedeling, E., M. Zhang, and E.H. Girvetz. 2009b. Climatic changes lead to declining winter chill for fruit and nut trees in California during 1950-2099. PLoS ONE 4:e6166.

Luedeling, E., M. Zhang, V. Luedeling, and E.H. Girvetz. 2009c. Sensitivity of winter chill models for fruit and nut trees to climatic changes expected in California's Central Valley. Agr. Ecosyst. Environ. 133:23-31.

Norvell, D.J. and J.N. Moore. 1982. An evaluation of chilling models for estimating rest requirements of highbush blueberries (Vaccinium corymbosum L.). J. Amer. Soc. Hort. Sci. 107: 54-56.

Rahemi, M. and Z. Pakkish. 2009. Determination of chilling and heat requirements of pistachio (Pistacia vera L.) cultivars. Agr. Sci. in China 8:803-807.

Richardson, E.A., S.D. Seeley, and D.R. Walker. 1974. A model for estimating the completion of rest for Redhaven and Elberta peach trees. HortScience 9:331-332.

Richardson, E.A., S.D. Seeley, D.R. Walker, J.L. Anderson, and G.L. Ashcroft. 1975. Phenoclimatography of spring peach bud development. HortScience 10:236-237.

Ruiz, D., J.A. Campoy, and J. Egea. 2007. Chilling and heat requirements of apricot cultivars for flowering. Environ. Exp. Bot. 61:254263.

Samish, R.M. 1954. Dormancy in woody plants. Annu. Rev. Plant Physiol. Plant Mol. Biol. 5: 183-204.

Saure, M.C. 1985. Dormancy release in deciduous fruit trees. Hort. Rev. 7:239-300.

Seeley, S.D. 1996. Modelling climatic regulation of bud dormancy, p. 361-376. In: Lang, G.A. (ed.). Plant dormancy. Wallingford, Oxon, UK.

Shaltout, A.D. and C.R. Unrath. 1983. Rest completion prediction model for Starkrimson delicious apples. J. Amer. Soc. Hort. Sci. 108: 957-961.

Stern, H., G. de Hoedt, and J. Ernst. 2000. Objective classification of Australian climates. Aust. Meteorol. Mag. 49:87-96.

Viti, R., L. Andreini, D. Ruiz, J. Egea, S. Bartolini, C. Iacona, and J.A. Campoy. 2010. Effect of climatic conditions on the overcoming of dormancy in apricot flower buds in two Mediterranean areas: Murcia (Spain) and Tuscany (Italy). Sci. Hort. 124:217-224.

Weinberger, J.H. 1950. Chilling requirements of peach varieties. Proc. Amer. Soc. Hort. Sci. 56: 122-128.

Yarnell, S.H. 1940. Texas studies on the cold requirement of peaches. Proc. Amer. Soc. Hort. Sci. 37:349-352.

Zhang, J. 2006. Distribution of flower cluster open. Acta Hort. 726:329-335. 